\title{
Carbon Weight Analysis for Machining Operation and Allocation for Redesign
}

Gaurav Ameta Mahesh Mani

Sudarsan Rachuri

Shaw C. Feng

Ram D. Sriram

Kevin W. Lyons

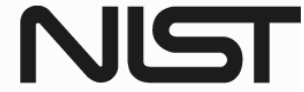

National Institute of Standards and Technology U.S. Department of Commerce 


\title{
Carbon Weight Analysis for Machining Operation and Allocation for Redesign
}

\author{
Gaurav Ameta \\ Mechanical and Materials Engineering \\ Washington State University \\ Mahesh Mani \\ Sudarsan Rachuri \\ Shaw C. Feng \\ Ram D. Sriram \\ Kevin W. Lyons \\ Manufacturing Systems Integration Division \\ Manufacturing Engineering Laboratory
}

December 2009

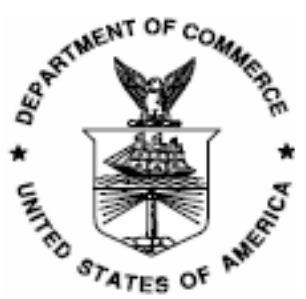

U.S. Department of Commerce Gary Locke, Secretary National Institute of Standards and Technology

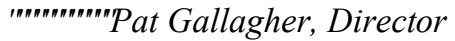




\section{Table of Contents}

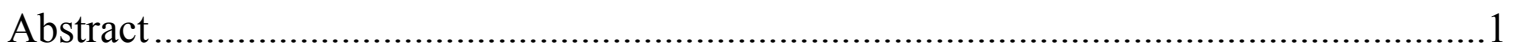

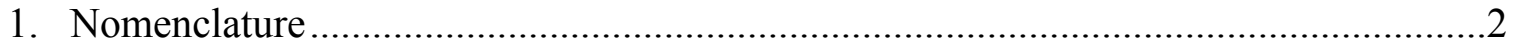

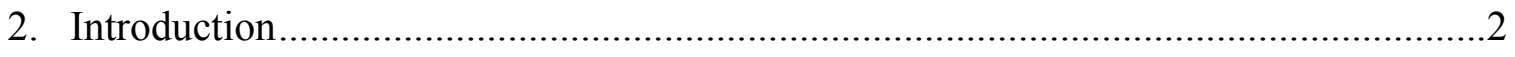

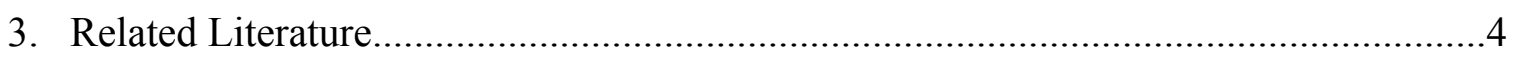

4. Carbon Weight Tolerancing Approach .................................................................

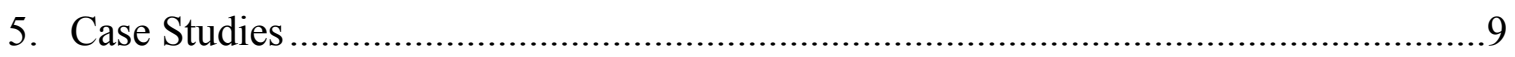

Case Study 1: Part Level CW ....................................................................

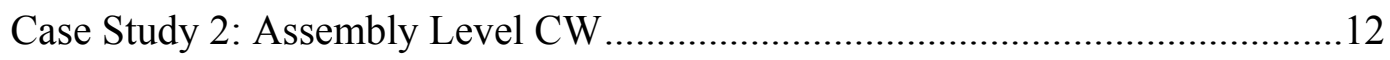

6. Carbon Weight Allocation/Synthesis............................................................. 14

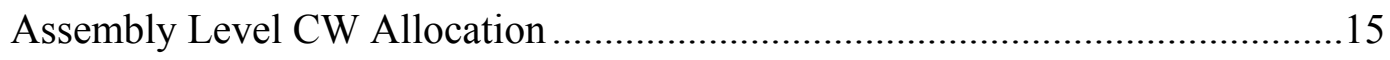

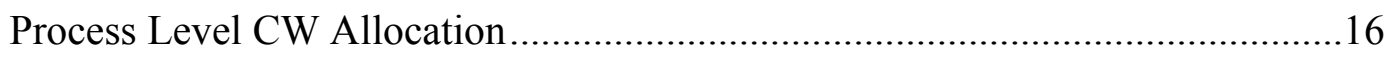

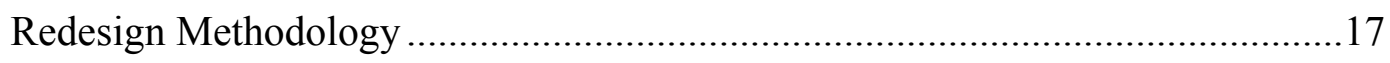

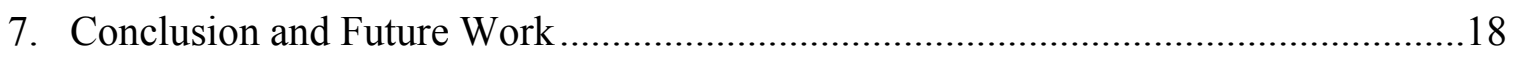

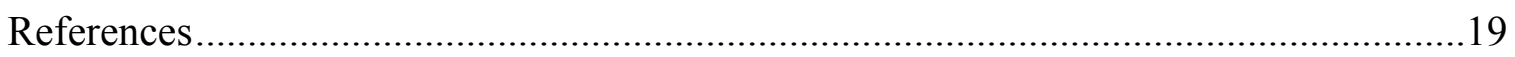

Appendix A: Worst Case and Statistical Case CW Computations ..................................21 


\section{List of Figures}

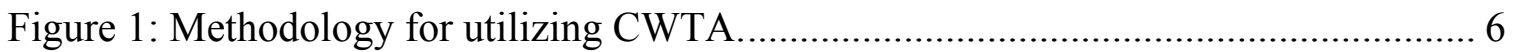

Figure 2: Carbon Weight Tolerancing Approach …………………………………….... 7

Figure 3: Test part 1 ……................................................................................. 9

Figure 4: Assembly ................................................................................................. 13

Figure 5: (a) Original and (b) redesigned Part A of the assembly (coupling) in Figure 4.15 Figure 6: Multi-level Form Material and Process Optimization (FMPO) based allocation of $\mathrm{CW}$ and redesign

\section{List of Tables}

Table 1: Computation of energy and CW from the specific energy ................................. 10

Table 2 Computation of energy and $\mathrm{CW}$ from the process parameters ............................ 11

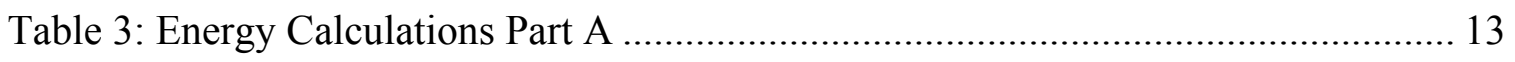

Table 4: Energy Calculations Part B.......................................................................... 14

Table 5: CW allocation based on 20\% reduction in CW for the assembly...................... 15

Table 6: CW values based on material and shape redesign for Part A of the assembly in

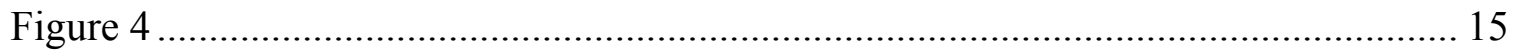

Table 7: Percent contribution for the process level CW example in section 5.1.2 All CW

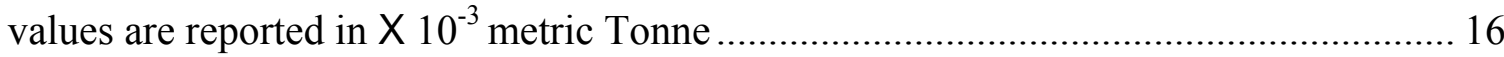




\title{
Carbon Weight Analysis for Machining Operation and Allocation for Redesign
}

\begin{abstract}
The objective of th is research is to explore and develop a new methodolog y for computing carbon weight (CW) - often referred to as carbon footprint, in manufacturing processes from the part leve $l$ to a ssembly le vel. In this in itial study we focused on machining operations, specifically turning and milling, for computing the CW. Our initial study demonstrates that $C W$ can be computed using either actual measured data from process level information or from initial material and manufacturing process information. In mechanical design, tolerance analysis principles extend from design to manufacturing and tolerances accumulate for parts and proces ses. By extending this notion to $C W$, we apply mechanical tolerancing prin ciples for computing worst case and statistical case CW of a product. We call this the CW To lerance Approach (CWTA). Two case studies demonstrate the computation of $\mathrm{CW}$. Base $d$ on toleran ce alloca tion concepts; $\mathrm{CW}$ allocation is also dem onstrated through specific redesign examples. CWTA helps in identifying carbon intensive parts/processes and can be used to make appropriate design decisions.
\end{abstract}

Keywords: Carbon footprint, Carbon Weight Analysis, Machining, Re-design 


\section{Nomenclature}

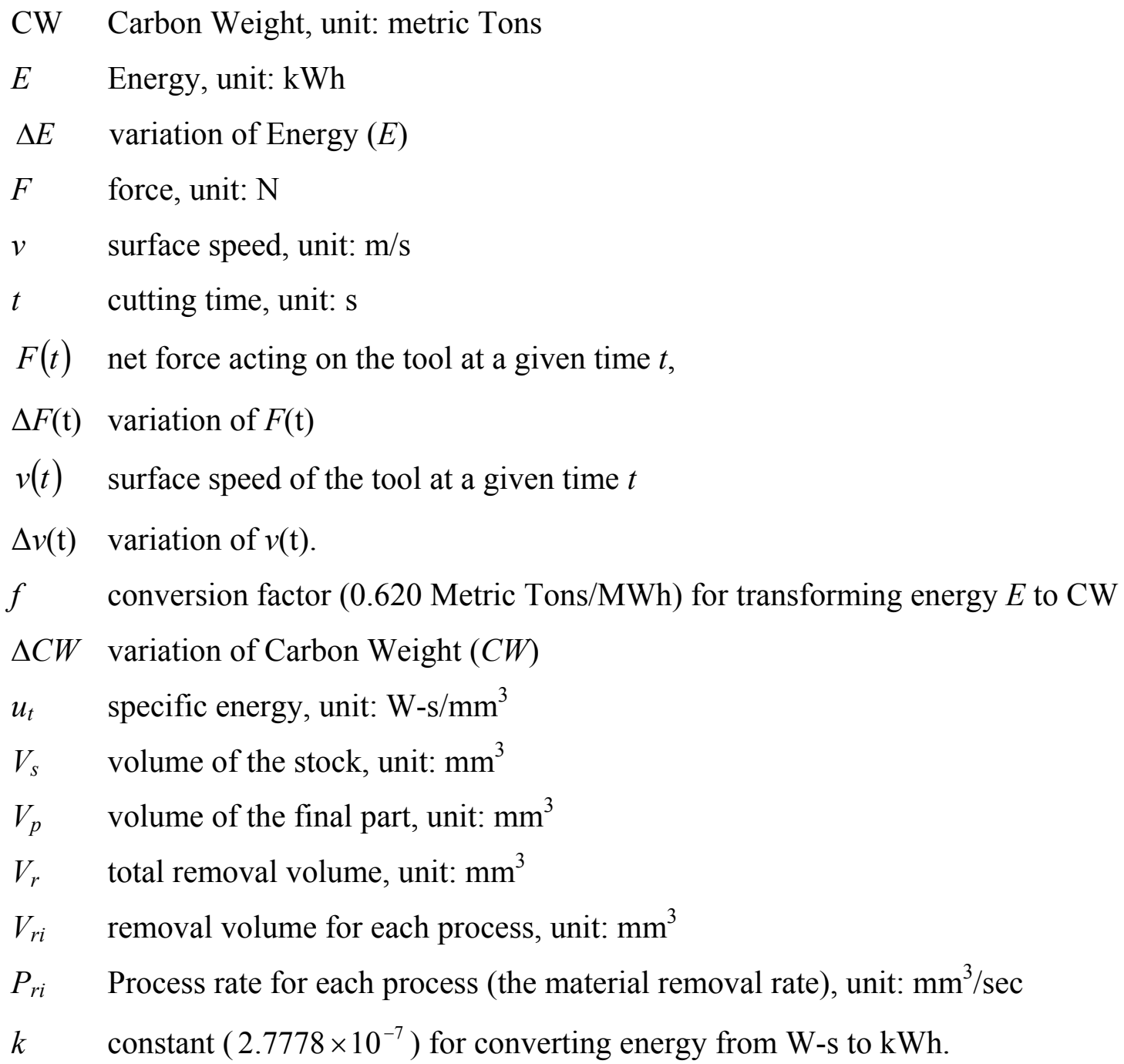

\section{Introduction}

In recent years, sustainable manufacturing has become a strategic move as industries began to seek novel ways for resource efficiency, ensure compliance with regulations related to environment and health, and enhance the marketability of their products and services. Energy is utilized at each stage of a product life cycle. Energy production from fossil fuels results in green house gas (GHG) emission. Hence minimization or efficient use of energy and resources are critical for reducing environmental effects of a product or process. 
Awareness, investments and efforts towards reducing greenhouse gases by industry, government and environmental organizations have increased in the last decade. The Kyoto Protocol, an international agreement linked to the United Nations Framework Convention on Climate Change, binds developed nations to a cap and trade system $^{1}$ for the emission of six major greenhouse gasses. Emission quotas were agreed by each participating country, with the intention of reducing their overall emissions to 1990 levels by the end of 2012. Under the agreement, for the 5-year compliance period from 2008 until 2012, nations that emit less than their quota will be able to sell emissions credits to nations that exceed their quota. In 2006, the European Union ETS (Emissions Trading Scheme) market traded 1,101 MtCO2e, Millions of tons of carbon dioxide equivalent. The carbon market grew in value to an estimated US\$30 billion in 2006 [27]. Therefore, a method to quantify green house gas emissions in products and process, especially $\mathrm{CO}_{2}$, is needed. At the G8 Summit which concluded in July 2008, the participating nations have pledged to move towards a low-carbon society and target the goal of at least $50 \%$ reduction in greenhouse gases by 2050 [1].

In this paper, we propose a methodology for computing Carbon Weight (CW), also called carbon footprint, as the metric for quantifying the $\mathrm{CO}_{2}$ emissions. Carbon footprint is defined as "a measure of the exclusive total amount of carbon dioxide emissions that is dir ectly and indirectly caused by an ac tivity or is accum ulated over the life stages of a product" [2]. In this preliminary study, we make an attempt to quantify the amount of $\mathrm{CO}_{2}$ emitted (in metric tons) from energy use in machining a part and compute the $\mathrm{CW}$ for the assembly, using mechanical tolerancing principles.

The paper is organized as follows: section 3 presents a related literature review. Section 4 presents the main concepts, assumption and proposed methodology. Section 5 presents two case studies, one at part level and the other at assembly level. Section 6 demonstrates the allocation methodology. Section 7 presents our conclusions and scope for future work.

\footnotetext{
${ }^{1}$ an administrative approach used to control pollution by providing economic incentives for achieving reductions in the emissions of pollutants
} 


\section{Related literature}

Standardized guidelines for assessing the environmental impacts, called life cycle assessment (LCA), have been developed by International Organization for Standardization (ISO) [3]. By including the impacts throughout the product life cycle, LCA provides a comprehensive view of the environmental aspects of the product or process. LCA has also been attributed with some drawbacks [4-8] related to (a) system boundaries issues, (b) data issues and (c) methodology issues such as weighing methods, aggregation methods and comparison across indices. Moreover, LCA only provides methodology for assessing the environmental impacts and does not provide any guidelines for reducing the impacts.

During a product's life cycle, energy is consumed at most of the stages; design, production, use and disposal. Energy use varies throughout a products life cycle and is different for different products. Energy accounting and reduction during product use (use phase) is governed by standards such as Energy Star [9], which supports a number of industries. Energy Star does not include the energy consumption during the manufacturing phase of a product life cycle. In this paper we present a methodology for accounting manufacturing phase energy and an initial attempt towards reducing the energy utilization during manufacturing.

Various studies $[10 ; 11]$ at the Department of Energy (DoE) focused on accounting the energy usage and emissions in different manufacturing industries. A study conducted by the National Association of Manufacturers (NAM, www.nam.org) speculated possible savings of about 19 billion dollars with development of new energy

efficient technologies [12]. Further details of energy-related carbon dioxide emissions in U.S. manufacturing were studied by Schipper [13].

Environmental impacts of different manufacturing processes have been extensively studied by Gutowski's research group [14-17]. They identify environmental impacts by accounting for the exergy of the manufacturing process. Exergy is defined as the potential of a system to cause a change as it achieves equilibrium with its environment (heat reservoir) [18]. When the environment is used as heat reservoir, exergy is the energy that is available to be used. Although exergy contains more information regarding energy losses to the environment, it is the use of energy during 
production that should be computed and then reduced for individual parts/component. Therefore, we choose to account for energy use instead of exergy. Moreover, Gutowski's research group focused mainly on identifying process related energy requirements and not energy specific to products.

Product related $\mathrm{CO}_{2}$ emission accounting has been reported by Jeswiet [19]. However, the author generalized the computation of $\mathrm{CO}_{2}$ factors from electricity requirements and did not consider the variability of different manufacturing processes. Jeswiet [19] also does not provide any extension to statistical analysis and utilization of $\mathrm{CW}$ analysis for the redesign of parts/assemblies. Furthermore, there is little work done on applying tolerancing scheme to $\mathrm{CW}$ calculations for machining an assembly of parts.

\section{Carbon Weight Tolerancing Approach}

In the proposed $\mathrm{CW}$ Tolerancing Approach (CWTA), we focus on the $\mathrm{CO}_{2}$ emissions based on the amount of energy consumed for manufacturing a part. Energy consumption is related to the power used due to the amount of removed volume, for specific material and associated manufacturing process.

Figure 1 presents the flow diagram for the methodology used in CWTA. The input is an assembly of parts with candidate material and manufacturing processes. In this current work we have not included the computation of $\mathrm{CW}$ for assembly processes, for example, welding, fixtures, transport, etc. We compute the amount of energy used in manufacturing a part based on the removed volume, material and manufacturing process. Due to variability associated with specific manufacturing environments and related data, energy consumption can only be computed as a range. If the range is quite large, based on the availability of the data, the computed $\mathrm{CW}$ range may not facilitate environmentally benign decisions. Therefore, in such cases, further investigation is needed for reducing the range. In this paper we are not investigating the range, but demonstrating the computation of $\mathrm{CW}$ assuming data availability is not an issue. The range of energy consumption can then be converted into the range of $\mathrm{CW}$ by using conversion tables provided by the Department of Energy (DOE) [20]. 


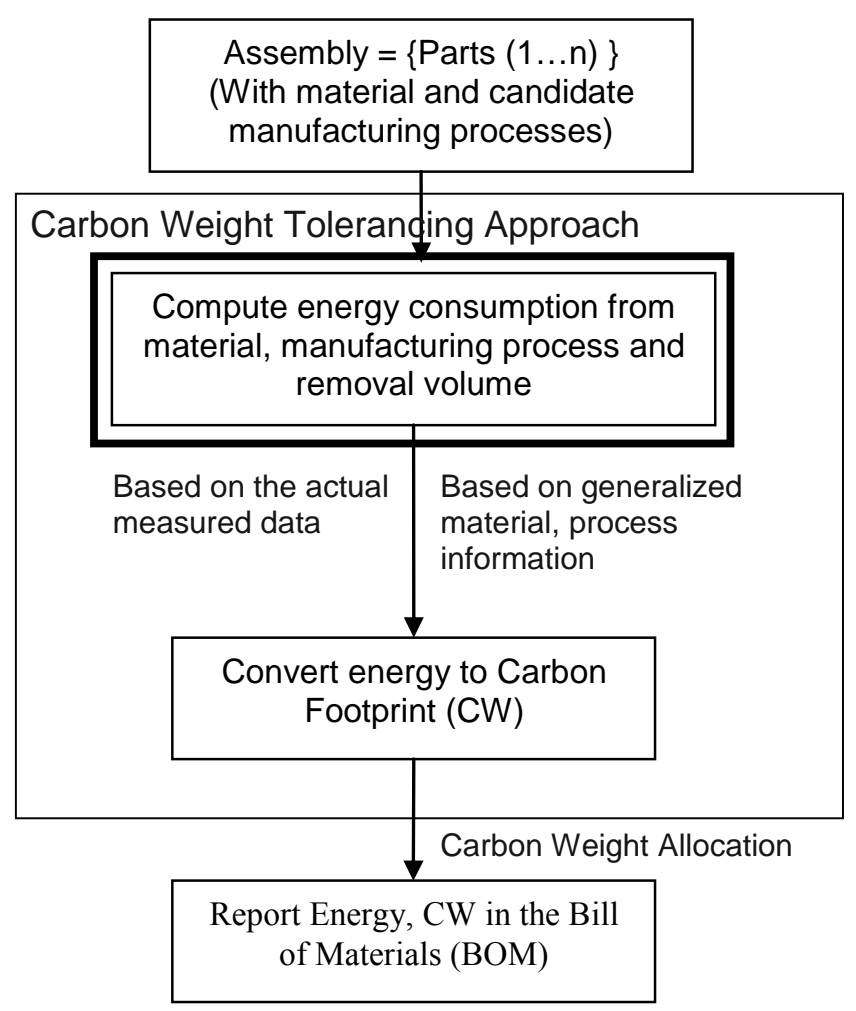

Figure 1: Methodology for utilizing CWTA.

The assembly level $\mathrm{CW}$ is computed using mechanical tolerancing principles, in terms of worst case and statistical scenario (Figure 2). The worst case $\mathrm{CW}$ reports the maximum and minimum carbon footprint for the assembly, while the statistical case reports the measured (or predicted) value of uncertainty for the range of the carbon footprint. For further details about computations related to worst case and statistical case $\mathrm{CW}$, please refer to Appendix A. The purpose of CWTA is to include CW information about the assembly and parts in the bill of materials $(\mathrm{BoM})$, thus creating a bill-of-carbon $(\mathrm{BoC})$. This $\mathrm{BoC}$, in conjunction with $\mathrm{CW}$ requirements, will then be utilized to improve the allocation of $\mathrm{CW}$ across the assembly (Figure 2) based on any functional requirements on the amount of $\mathrm{CW}$ for the given product. The $\mathrm{CW}$ allocation could be performed using percentage contribution or sensitivity of individual parts/features towards the total $\mathrm{CW}$. CWTA would therefore help in identifying carbon intensive parts/processes and can be used to make appropriate design decisions. In future, we hope to extend CWTA for information exchange between CAD/PLM tools to LCA tools and this allowing integration of environmental aspects into product design and development. 


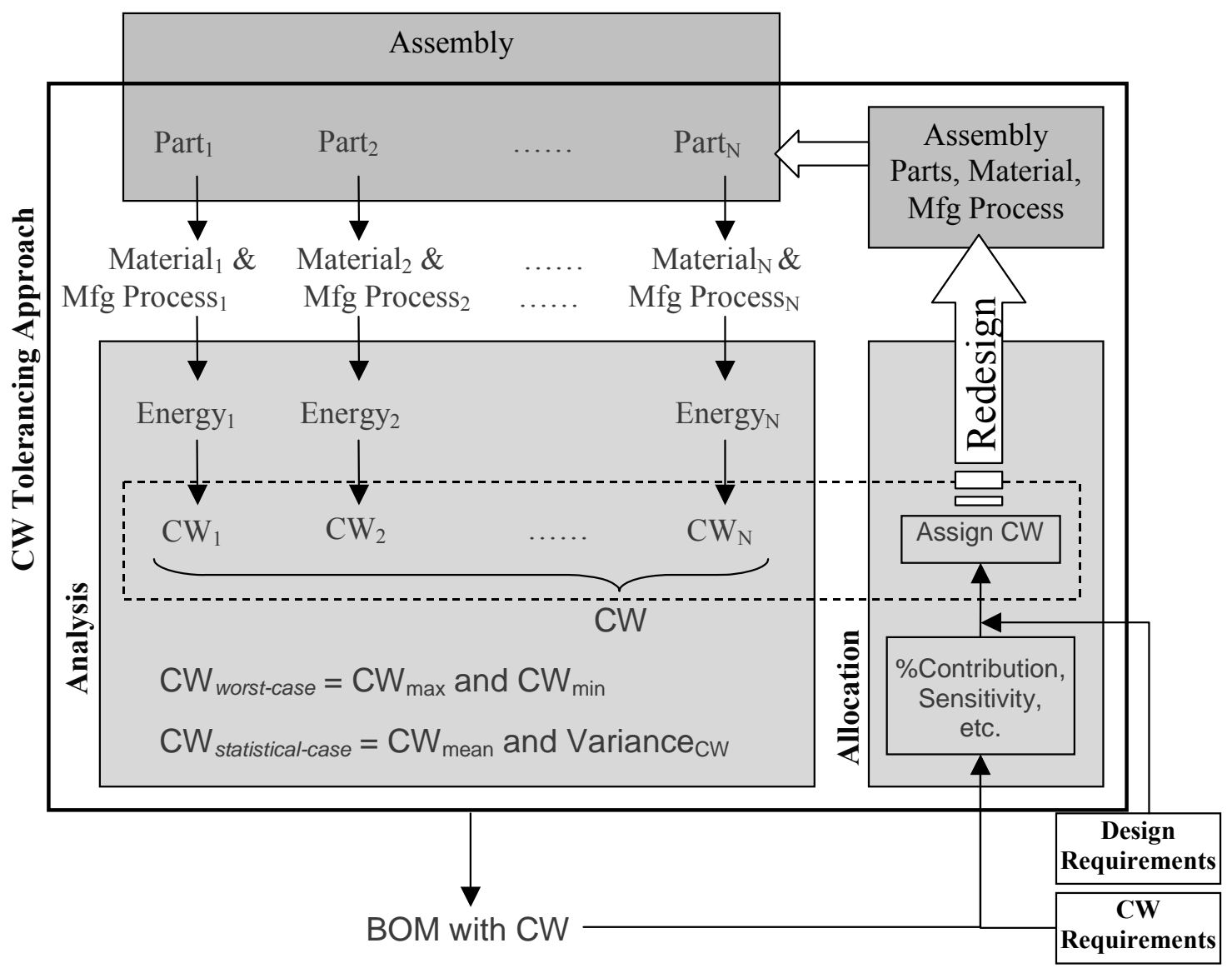

Figure 2: Carbon Weight Tolerancing Approach

We now present generalized CWTA computations for a part; (a) based on the actual process level measured data (experimental) and (b) based on the initial material and manufacturing process information.

a) CWTA computation based on the actual process level measured data

If process parameters, namely cutting forces, surface speeds, process time, etc., from actual machining operations are available, they can be utilized to compute the energy consumed. Energy can be computed using the force, surface speed and cutting time as

$$
E=k \int_{t_{0}}^{t_{1}} F(t) * v(t) d t
$$

Please refer to the nomenclature section for the meanings of the symbols used. Since all measuring instruments have variability in the measured values, the measured $F$ and $v$ would be range of values. Therefore, the resultant energy E would also be computed as a 
mean and variation. The variation in energy $\Delta E$ due variation in the measurement of force and surface speed can be computed as:

$$
E \pm \Delta E=k \int_{t_{0}}^{t_{1}}(F(t) \pm \Delta F(t)) *(v(t) \pm \Delta v(t)) d t
$$

A precision machining center has very good control on velocity, so $\Delta v(\mathrm{t})$ is very small and can be neglected. The $\mathrm{CW}$ of the machining process can then be computed as

$$
C W \pm \Delta C W=f(E \pm \Delta E)
$$

Basically $\mathrm{CW}$ is proportional to $\mathrm{E}$ and the proportionality factor is $f$. Energy Information Administration (EIA) under the U.S. Department of Energy (DOE), have reported a methodology and related tables for computing factor $f$ [20]. For Maryland the value of $f$ is 0.620 Metric Tons/mWh. EIA reports $\mathrm{CO}_{2}$ emission in terms of metric tons.

Ivester et al. [21] at NIST have earlier provided characterization and optimization of specific manufacturing processes and provided useful data based on their test part, not an assembly of parts. In this study we use the experimental data from [21].

b) CWTA computation based on the initial material and manufacturing process information

In the absence of specific process parameters, generalized energy consumption for cutting operation, given by Kalpakjian [22], in the form of specific energy will be utilized. The specific energy is energy per unit time required for removing a unit volume from a given material. By obtaining the total removal volume, energy will be obtained as

$$
E=k V u_{t}
$$

For a given machining process, based on the machine, tool, material, stock and removal volume we will estimate the amount of energy utilized for producing a part. $\mathrm{CW}$ will then be computed using equation (2). 


\section{Case Studies}

To demonstrate the CWTA methodology, we present two case studies, one at the part level and the second at the assembly level. In both cases we first compute the removal volume, then calculate the energy consumed and finally convert the energy to $\mathrm{CW}$. In the subsequent subsections we present the $\mathrm{CW}$ computations for the individual cases based on the two methods discussed in the previous section.

Our assumptions specific to the CWTA case studies are:

- Turning and milling have been selected as the candidate manufacturing processes.

- Only rough estimates for $\mathrm{CO}_{2}$ emissions, based on energy use during manufacturing, will be provided.

- Stock is always assumed to be properly rounded (for turning operations).

\subsection{Case study 1: Part Level CW}

We choose test part 1 (Figure 3) specifically to demonstrate the CW computation using the two approaches mentioned in the previous section. The experimental data for the turning operations has been taken from Ivester et al. [21]. The reported material is AISI 1045 Steel and all experiments were performed on a $22 \mathrm{~kW}$ lathe by Ivester et al. [21].
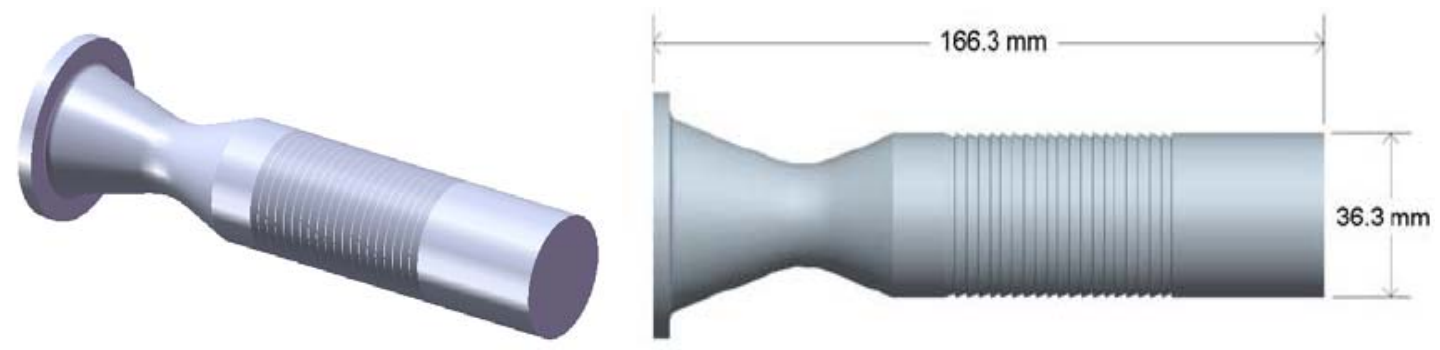

Figure 3: Test part 1

We have adopted the specific energy data for cutting operations from [22] and have also compared with the data from [15]. The data available in [15] is not specific to particular material and is an average data for $1000 \mathrm{hrs}$ of machine run. 


\subsubsection{CW based on material and manufacturing process information}

Table 1 summarizes the available data and the computed results for the test part shown in Figure 3. Subtracting the volume of the stock $\left(V_{s}\right)$ and final part $\left(V_{p}\right)$ gives the removal volume $\left(V_{r}\right)$. The specific energy $\left(u_{t}\right)$ range as reported in [22] for the given material is 2.7-9.3 W-s $/ \mathrm{mm}^{3}$. As reported in [22], the value of specific energy is for dull tools and $80 \%$ efficient drive motor. Therefore, we also report a modified specific energy data for sharp tools and fully efficient motor as $2.16-7.44 \mathrm{~W}-\mathrm{s} / \mathrm{mm}^{3}$. The specific energy data from [15] is also shown.

Table 1: Computation of energy and CW from the specific energy

\begin{tabular}{|c|c|c|c|}
\hline Volume of the Stock $\left(V_{s}, \mathrm{~mm}^{3}\right)$ & \multicolumn{3}{|l|}{581266} \\
\hline Volume of the Part $\left(V_{p}, \mathrm{~mm}^{3}\right)$ & \multicolumn{3}{|l|}{145397} \\
\hline Removal Volume $\left(V_{r}, \mathrm{~mm}^{3}\right)$ & \multicolumn{3}{|l|}{$V_{s}-V_{p}=435869$} \\
\hline \multirow[t]{2}{*}{ Specific energy $\left(u_{t}, W-s / \mathrm{mm}^{3}\right)$} & From [22] & $\begin{array}{l}\text { From }[22], \\
\text { corrected for sharp } \\
\text { tools }\end{array}$ & $\begin{array}{l}\text { From [15] (Total } \\
\text { energy, material } \\
\text { independent) }\end{array}$ \\
\hline & $2.7-9.3$ & $(2.16-7.44)$ & $3.5-15$ \\
\hline Energy Consumption $(k W h)$ & $0.3269-1.1260$ & $0.2615-0.9$ & $0.4237-1.8161$ \\
\hline $\mathrm{CW} \times 10^{-4},($ metric Tons $)$ & $2.02678-6.9812$ & $1.6214-5.5849$ & $2.627-11.26$ \\
\hline
\end{tabular}

Now utilizing equation (3) and the data from Table 1, energy consumption and $\mathrm{CW}$ (for turning the part shown in Figure 3) is computed as shown in the last two rows of Table 1.

\subsubsection{CW based on experimental data}

We approximate the process time $\left(t_{i}\right)$ by computing the removal volume $\left(V_{r i}\right)$ for each process and the material removal rate $\left(P_{r i}\right)$ given by Ivester et al. [21]. Due to lack of information regarding the time dependent variation of force $(F)$, surface speed $(v)$ and material removal rate $\left(P_{r i}\right)$, we assume these process parameters to be constant. Therefore, we drop the integration in equation (2) and approximate it as shown in equation (5).

$$
E \pm \Delta E=k(F \pm \Delta F) v t=k(F \pm \Delta F) v \frac{V_{r i}}{P_{r i}}
$$


Utilizing the assumptions and equation (5) we compute the energy and the CW of the part as shown in Table 2 .

Table 2 Computation of energy and CW from the process parameters

\begin{tabular}{|l|r|r|r|r|r|r|r|}
\hline Operation & $\mathbf{F ~ ( N )}$ & $\begin{array}{r}\boldsymbol{v} \\
(\mathbf{m} / \mathbf{s e c})\end{array}$ & $\begin{array}{r}\text { Process } \\
\text { Rate } \\
\left(\mathbf{m m}^{3} / \mathbf{s e c}\right)\end{array}$ & Power (W) & $\boldsymbol{t}(\mathbf{s e c})$ & $\begin{array}{r}\text { Nominal } \\
\text { Energy } \\
(\mathbf{K W H})\end{array}$ & $\begin{array}{r}\text { CW } \\
\mathbf{1 0}^{-4}\end{array}$ \\
\hline $\begin{array}{l}\text { Rough OD } \\
\text { (Outer } \\
\text { Diameter) }\end{array}$ & $742 \pm 5$ & 3.11 & 989.50 & $2307.62 \pm 15.55$ & 294.64 & 0.1889 & \\
\hline $\begin{array}{l}\text { Rough } \\
\text { Grooves }\end{array}$ & $204 \pm 4$ & 4.26 & 426.67 & $869.04 \pm 17.04$ & 61.21 & 0.0148 & $0.1171 \pm 0.0008$ \\
\hline $\begin{array}{l}\text { Rough } \\
\text { Contour }\end{array}$ & $221 \pm 3$ & 2.16 & 216.67 & $477.36 \pm 6.48$ & 250.32 & 0.0332 & $0.0092 \pm 0.0002$ \\
\hline $\begin{array}{l}\text { Finish OD } \\
\text { (Outer } \\
\text { Diameter) }\end{array}$ & $36 \pm 2$ & 3.16 & 63.33 & $113.76 \pm 6.32$ & 236.98 & 0.0075 & $0.0206 \pm 0.0003$ \\
\hline $\begin{array}{l}\text { Finish } \\
\text { Grooves }\end{array}$ & $74 \pm 2$ & 3.33 & 100.00 & $246.42 \pm 6.66$ & 268.48 & 0.0184 & $0.0046 \pm 0.0003$ \\
\hline $\begin{array}{l}\text { Finish } \\
\text { Contour }\end{array}$ & $76 \pm 2$ & 1.83 & 55.00 & $139.08 \pm 3.66$ & 402.08 & 0.0155 & $0.0114 \pm 0.0003$ \\
\hline
\end{tabular}

The total energy and CW can be computed by adding the energy and CW of individual process, respectively. The total energy consumed is $0.2782 \pm 0.0033$ (see Appendix A for further details regarding this calculation) $\mathrm{kWh}$ and the total $\mathrm{CW}$ is $(1.7251 \pm 0.0208) \times 10^{-4}$ metric tons of $\mathrm{CO}_{2}$.

\subsubsection{Comparison}

The data from [15] represent the specific energy during the entire manufacturing process including machine idle energy, coolant flow energy, etc. This data is not specific to a material and is only based on process information. The data from [22] also represents the specific energy during the entire manufacturing process including machine idle energy, coolant flow energy, but is specific for a particular material. The data from [21] represents the specific cutting energy and does not include idle energy, coolant flow 
energy, etc. The data from [15], [22] and [21] follows from a general to a specific level of detail. Thus, the $\mathrm{CW}$ computed using the data from [15] should form an upper bound to the computed $\mathrm{CW}$ value using the data from [21]. The value of $\mathrm{CW}$ computed using data from [21], $\left(1.7 \times 10^{-4}\right)$, is well below the value of $\mathrm{CW},\left(2.6 \times 10^{-4}\right)$, computed using the data from [15].

Moreover, the data in [22] assumes normal cutting operations, viz., blunt tools and $80 \%$ efficiency of the drive motor. Since, the experimental data provided by Ivester et al. [21] was measured using specific and sharp tools (to maintain the required surface roughness), a valid comparison can only be made if the data from [22] is corrected for sharp tools. The third column in Table 1 shows the computation using the corrected data for sharp tools. The range of CW (1.6214-5.5849) $\times 10^{-4}$ computed from the corrected data now bounds the $\mathrm{CW}$ value $(1.7251 \pm 0.0208) \times 10^{-4}$ computed using the data from [21]. Therefore, we can conclude that the data provided in [22] can be used to approximate $\mathrm{CW}$ values at the initial design stages.

The relative closeness in range between the two approaches indicates the potential application of the proposed methodology for $\mathrm{CW}$ calculation, subject to the availability of reliable data. This initial experiment identifies a need to characterize the processes so that accurate $\mathrm{CW}$ can be computed.

\subsection{Case study 2: Assembly Level CW}

In this case study we present the application of CWTA for an assembly based on material and manufacturing process information. The function of the assembly is to provide torque transfer and alignment between two rotating components. Figure 4 presents the assembly (coupling) and exploded view of the assembly used in the case study. The function of the coupling is to align two rotating shafts and to transmit the motion from one shaft to another. Tables 3 and 4 present the removed volume based on the machining operation for the individual parts of the assembly. The pins are assumed to be supplied by a supplier; therefore the energy consumed in producing the pins is ignored. We assumed AISI 304 Steel as the part material and hence the corresponding specific energy range is 3.0 to $5.2 \mathrm{~W}-\mathrm{s} / \mathrm{mm}^{3}$ [22]. 


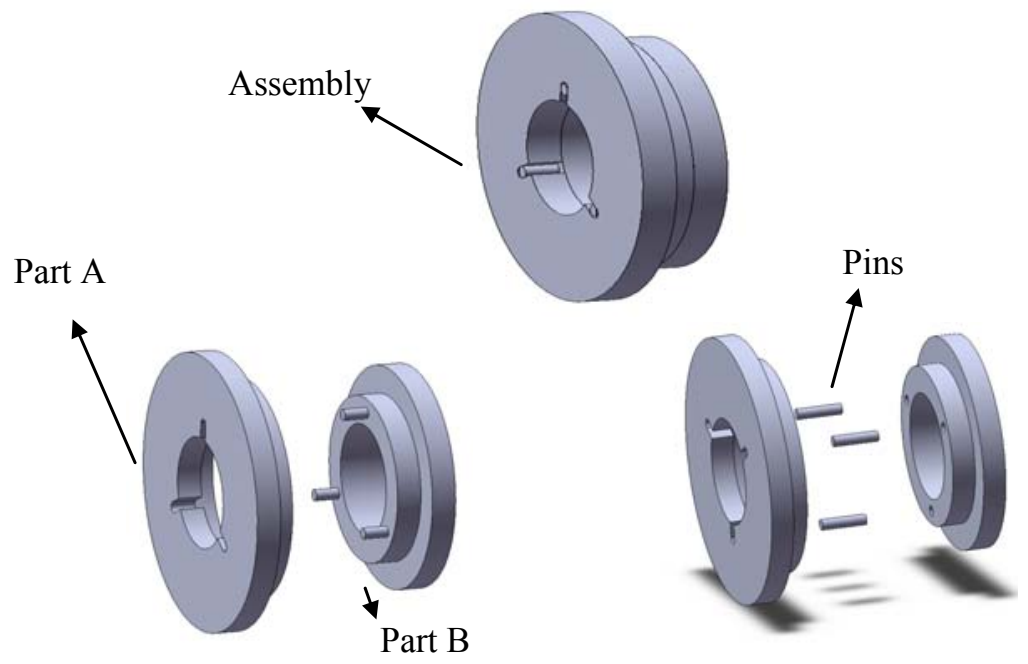

Figure 4: Assembly

Table 3: Energy Calculations Part A

\begin{tabular}{|l|l|l|l|l|}
\hline & & \\
\hline
\end{tabular}

Utilizing equation (4), the energy consumption for each of the parts can be computed. Energy consumption for Part A $=0.0820-0.2824 \mathrm{kWh}$. This energy can be converted to $\mathrm{CW}$ by using equation (3) as a range from $0.0508 \times 10^{-3}$ to $0.1751 \times 10^{-3}$ metric tons of $\mathrm{CO}_{2}$. Similarly, energy consumption for Part $\mathrm{B}=0.0556-0.1917 \mathrm{kWh}$ and this energy can be converted to $\mathrm{CW}$ by using equation (3) as a range from $0.0345 \times 10^{-3}$ to $0.1188 \times 10^{-3}$ metric tons of $\mathrm{CO}_{2}$.

From equations (A-1) to (A-4) in Appendix A, the worst-case CW range for the assembly can be computed as $0.0853 \times 10^{-3}-0.2939 \times 10^{-3}$ metric tons of $\mathrm{CO}_{2}$. From equations (A-1) and (A-5) in Appendix A, the statistical case CW mean and standard 
deviation for the assembly can be computed as $0.1896 \times 10^{-3}$ metric tons of $\mathrm{CO}_{2}$ and 0.0347 , respectively. Note that while computing the $\mathrm{CW}$ for the statistical case, due to the lack of data, we choose normal distribution as a candidate distribution over the range of $\mathrm{CW}$ on individual parts. We limited ourselves to normal distribution to simplify the computations. In future other distributions can also be explored and validated [23].

Table 4: Energy Calculations Part B

\begin{tabular}{|l|l|l|l|l|}
\hline & & &
\end{tabular}

\section{Carbon Weight Allocation/Synthesis}

For an eco-friendly product, reduction in the $\mathrm{CW}$ of the individual parts and assembly is desired. To begin with, a reduction of, say, $\mathrm{X} \%$ can be targeted for the whole assembly. The target $\mathrm{CW}$ for the assembly can then be allocated to individual parts/features, and later utilized for redesign of individual parts/assembly. For allocation of $\mathrm{CW}$ to individual parts, percent contribution or sensitivity of the $\mathrm{CW}$ of individual parts/features can be utilized. The percent contribution of individual parts/features should be computed while CWTA is completed. The basic idea is to identify carbon intensive parts/components and make appropriate design decisions and we may not need detailed design - we could use data from similar products.

In the subsequent section we would demonstrate the application of $\mathrm{CW}$ allocation for redesign of assembly and manufacturing process. A methodology is suggested for redesign based on $\mathrm{CW}$ allocation.

\subsection{Assembly Level CW Allocation}


As an example of assembly level CW allocation, Table 5 shows the allocated values of $\mathrm{CW}$ for individual parts from the assembly in Figure 4. For demonstration, allocation is done based on a $20 \%$ reduction in CW for the assembly. The allocated values can then be used to redesign an eco-friendly product. The reduced value of $\mathrm{CW}$ can later potentially used in an eco-label. Figure $5 \mathrm{a}$ and $\mathrm{b}$ shows the original design and one of the redesign choices available for Part A.

Table 5: CW allocation based on $20 \%$ reduction in CW for the assembly

\begin{tabular}{|l|l|l|l|l|l|}
\hline & \multicolumn{2}{|l|}{ Initial CW $\left(0^{-3}\right.$ metric Tonne $)$} & \% Cont. & \multicolumn{2}{l|}{ Allocated CW(X 10 $0^{-3}$ metric Tonne $)$} \\
\hline & Min & Max & & Min & Max \\
\hline Part A & 2.8631 & 4.9624 & 59.542 & 2.2904 & 3.9699 \\
\hline Part B & 1.9454 & 3.3691 & 40.457 & 1.5563 & 2.6952 \\
\hline Assembly & 4.8085 & 8.3315 & 100 & 3.8468 & 6.6652 \\
\hline
\end{tabular}

The redesigned Part A as shown in Figure 5(b), a) consists of closed slots, instead of open ones and b) has material around the rim that has not been machined. The function of the assembly in Figure 4, is to align two rotating shafts and to transfer the motion of one shaft to another. The new design (Figure 5(b)), does not affect the function of the assembly. The redesign solution, shown in Figure 5(b), is solely intended to demonstrate the methodology for $\mathrm{CW}$ allocation. Actual selection of a particular redesign would require additional considerations like function, material requirements, strength, cost, general assembly, etc.
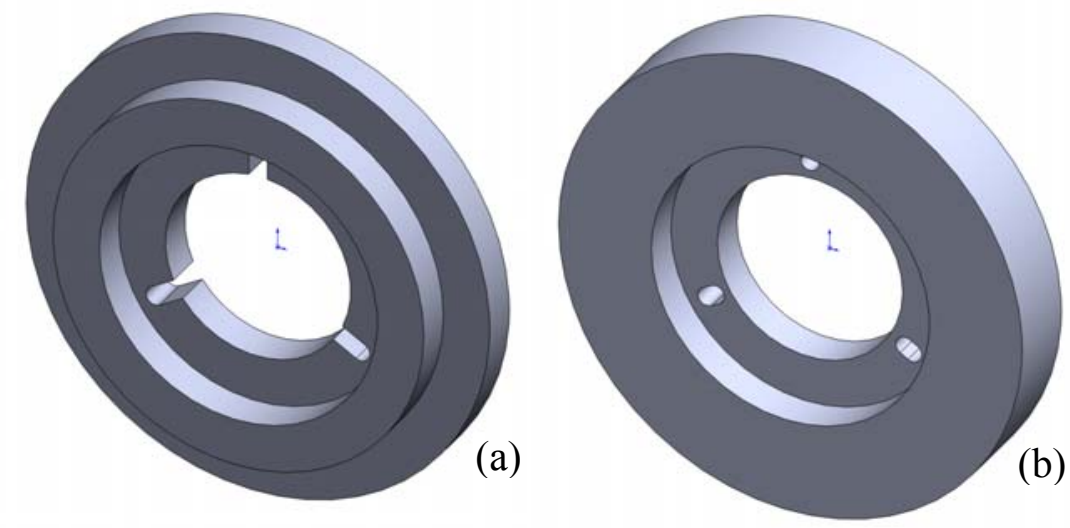

Figure 5: (a) Original and (b) redesigned Part A of the assembly (coupling) in Figure 4.

Table 6: $\mathrm{CW}$ values based on material and shape redesign for Part A of the assembly in Figure 4

\begin{tabular}{|l|l|}
\hline & Calculations \\
\hline
\end{tabular}




\begin{tabular}{|l|l|l|l|l|}
\hline Geometry & \multicolumn{2}{|l|}{ For open slots } & \multicolumn{2}{l|}{ For closed slots } \\
\hline Volume of the Part & $136093.89 \mathrm{~mm}^{3}$ & $180659.33 \mathrm{~mm}^{3}$ \\
\hline Removed Volume & $109343.04 \mathrm{~mm}^{3}$ & $64777.60 \mathrm{~mm}^{3}$ \\
\hline Material & Steel & Aluminum & Steel & Aluminum \\
\hline Energy for Machining $(\mathrm{kWh})$ & $0.0820-0.2824$ & $0.0121-0.0334$ & $0.0485-0.1673$ & $0.0071-0.0197$ \\
\hline $\begin{array}{l}\text { Carbon Weight } \\
\left(\mathrm{X} 10^{-3} \text { metric Tons }\right)\end{array}$ & $0.0508-0.1751$ & $0.0075-0.0207$ & $0.0301-0.1037$ & $0.0044-0.0122$ \\
\hline
\end{tabular}

Table 6 shows the values of CW and energy for the redesigned Part A. CW for two choices of material is also compared for the original and redesigned Part A. The sample calculations in Table 6 and the redesigned Part A in Figure 5b shows the choices that can be provided to the decision maker based on CW. As earlier mentioned, the final selection of a particular design would further involve a multi-constraint optimization scheme based on different requirements.

\subsection{Process Level CW Allocation}

$\mathrm{CW}$ allocation can also be extended to a manufacturing process level, for process level optimization. Table 7 shows a machining example for the process level allocation based on $80 \%$ reduction in $\mathrm{CW}$ from the example discussed in section 5.1.2.

Table 7: Percent contribution for the process level CW example in section 5.1.2 All $C W$ values are reported in $X 10^{-3}$ metric Tonne

\begin{tabular}{|l|r|r|r|}
\hline Operation & \multicolumn{1}{|l|}{ CW Process } & \% contribution & \multicolumn{1}{|l|}{$\begin{array}{l}\text { Allocated CW based on 20\% } \\
\text { reduction in CW }\end{array}$} \\
\hline Rough OD & 0.1171 & 67.88405797 & 0.09368 \\
\hline Rough Grooves & 0.0092 & 5.333333333 & 0.00736 \\
\hline Rough Contour & 0.0206 & 11.94202899 & 0.01648 \\
\hline Finish OD & 0.0046 & 2.666666667 & 0.00368 \\
\hline Finish Grooves & 0.0114 & 6.608695652 & 0.00912 \\
\hline Finish Contour & 0.0096 & 5.565217391 & 0.00768 \\
\hline Total & 0.1725 & 100 & 0.138 \\
\hline
\end{tabular}

For sample calculations in Table 7, equal weights were for each individual process (roughing, finishing, etc). Different weights can actually be utilized for the actual process 
optimization based on the requirements for individual steps. A process optimization scheme as discussed in [21] could potentially utilize such allocated values of CW.

\subsection{Redesign Methodology}

Figure 6 demonstrates a framework for utilizing $\mathrm{CW}$ in redesign of an assembly at different levels, viz., form, material and process. Redesign at these three levels flows from top down. Any change in form would require changes in material and manufacturing processes for satisfying the design requirements. Any change in material may require changes in manufacturing processes.

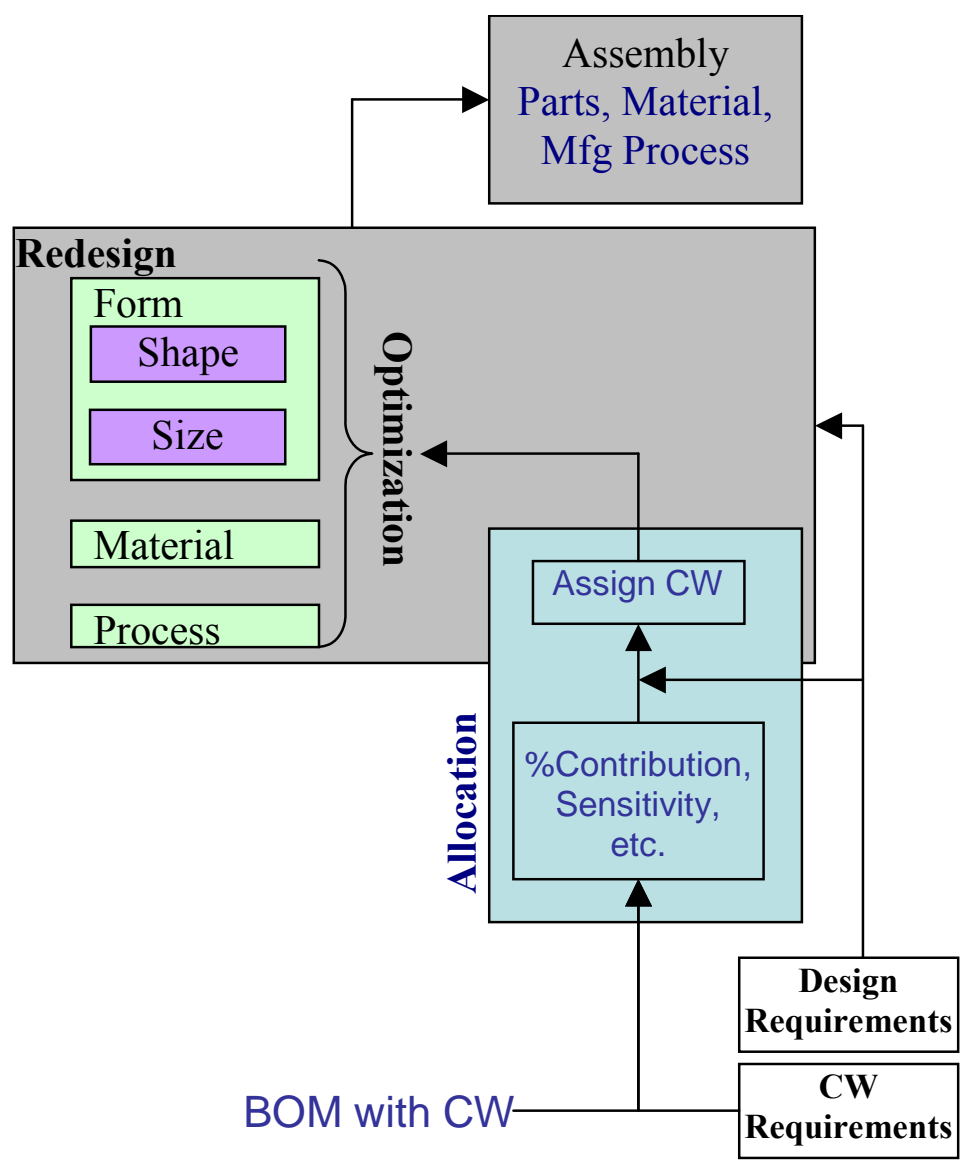

Figure 6: Multi-level Form Material and Process Optimization (FMPO) based allocation of $\mathrm{CW}$ and redesign

In the methodology shown in Figure 6, form redesign implies changes in shape and size of the design. Material redesign could indicate either selecting different material or designing new material to meet the design requirements. Manufacturing process redesign would indicate changes in process, setups, operations, tools, fixture etc. 
Therefore, redesign based on $\mathrm{CW}$ allocation would require a multi-level form, material and process optimization.

\section{Conclusions and Future Work}

In this research, we have utilized and extended the mechanical tolerancing principles of assembly level analysis for computing a product's carbon weight (CW). Such $\mathrm{CW}$ estimates can be utilized during the design evaluation stages of a product to make environmentally friendly decisions both regarding the product and the manufacturing process. This research work is a first step towards demonstrating the CWTA and the corresponding computations. The presented case studies indicate CWTA as a potential application for $\mathrm{CW}$ calculation.

In future we would like to demonstrate CWTA for CW allocation through software application. Furthermore, we would like to investigate the data issues and metrology concepts (measurement methods, uncertainty, calibration, etc.) for $\mathrm{CW}$. Identification of scopes for practical application and best practices for $\mathrm{CW}$ tolerance analysis and synthesis at successive stages of design will also be pursued in the future.

\section{Acknowledgements}

We wish to express our thanks to Dr. Alkan Donmez for participating in our earlier discussions and offering valuable insights to this research.

\section{DISCLAIMER}

No approval or endorsement of any commercial product by the National Institute of Standards and Technology is intended or implied.

\section{References}

1. G8 Hokkaido Toyako Summit Leaders Declaration. http://www.g8summit.go.jp/eng/doc/doc080714_en.html . 7-8-2008.

2. Wiedmann T, and Minx J, "A Definition of 'Carbon Footprint'," ISAUK Research Report 07-01, Jan. 2007. 
3. "ISO 14001:2004, Environmental management systems -- Requirements with guidance for use," ISO, International Organization for Standardization (ISO), Geneva, Switzerland, 2004.

4. Haes, H. U. d., "Applications of life cycle assessment: expectations, drawbacks and perspectives.," Journal of Cleaner Production, Vol. 1, No. 3-4, 1993, pp. 131-137.

5. Mayer A.L., "Strengths and weakness of common sustainability indices for multidimensional systems," Environment International, Vol. 34, No. 2, 2008, pp. 277-291.

6. Coatanéa, E., Kuuva, M., Makkonen, P., and Saarelainen, T., "Environmental analysis of the Product Life Cycle by using an aggregated metric based on exergy," International Journal of Product Lifecycle Man agement, Vol. 2, No. 4, 2007, pp. 337-355.

7. Lenzen, M., "Errors in Conventional and Input-Output-based Life-Cycle Inventories," Journal of Industrial Ecology, Vol. 4, No. 4, 2001, pp. 127-148.

8. Strømman, A. H., Peters, G. P., and Hertwich, E. G., "Approaches to correct for double counting in tiered hybrid life cycle inventories," Journal of Cleaner Production, 2008.

9. ENERGYSTAR. http://www.energystar.gov/ . 2008.

10. "Energy and Environmental Profile of the U.S. Metalcasting Industry," US Department of Energy, Sept. 999.

11. "U.S. Energy Requirements for Aluminum Production: Historical Perspective, Theoretical Limits and New Opportunities," US Department of Energy Efficiency and Renewable Energy, Jan. 2003.

12. "Efficiency and Innovation In U.S. Manufacturing Energy Use," National Association of Manufacturers, 2005.

13. Schipper, M., "Energy-Related Carbon Dioxide Emissions in U.S. Manufacturing," Department of Energy, DOE/EIA-0573(2005), 2005.

14. Gutowski, T., Dahmus, J., Thiriez, A., Branham, M., and Jones, A., "A Thermodynamic Characterization of Manufacturing Processes," Orlando, Florida, USA,2007.

15. Gutowski, T., Dahmus, J., and Thiriez, A., "Electrical Energy Requirements for Manufacturing Processes," Leuven, Belgium,2006.

16. Gutowski, T., Dahmus, J., and Dalquist, S., "Measuring the Environmental Load of Manufacturing Processes," Stockholm, Sweden,2005. 
17. Dahmus, J., and Gutowski, T., "An Environmental Analysis of Machining," Anaheim, California, USA,2004.

18. Perrot, P., A to Z of Thermodynamics, Oxford University Press 1998.

19. Jeswiet, J., "Carbon Emissions and CES in Manufacturing," Sydney, Australia, 2008.

20. "Updated State-level Greenhouse Gas Emission Coefficients for Electricity Generation 1998-2000," Energy Information Administration, Office of Integrated Analysis and Forecasting, Energy Information Administration, U.S. Department of Energy, 2002.

21. Ivester, R. and Heigel, J., "Smart Machining Systems: Robust Optimization and Adaptive Control Optimization for Turning Operations," Transcations of NAMRI/SME, Vol. 35, 2007, pp. 505-512.

22. Kalpakjian, S., Manufacturing Engineering and Technology , 3rd edition ed., Addison-Wesley publishing co.1995.

23. Sudarsan, R., Narahari, Y., Roy, U., Sriram, R. D., Lyons, K. W., and Pramanik, N., "Information Models for Design Tolerancing: from conceptual to the detail design," National Institute of Standards and Technology, Gaithersburg, MD 20899, USA, 1999.

24. Evans, D. H., "A Statistical Tolerancing Formulation," Journal of Quality Technology, Vol. 2, No. 4, 1970, pp. 226-231.

25. Evans, D. H., "Statistical Tolerancing: State of the Art, Part 1. Background," Journal of Quality Technology, Vol. 6, No. 4, 1974, pp. 188-195.

26. Ross, S., A First Course in Probability, Prentice Hall2005.

27 Capoor K. and Ambrosi P., "State and Trends of the Carbon Market", The World Bank, Washington DC, May 2007

\section{Appendix A: Worst Case and Statistical Case CW Computations}

In this appendix we extend the ideas from tolerance analysis to $\mathrm{CW}$ analysis in assemblies. The basic ideas borrowed from tolerance analysis will be explained in the subsequent paragraphs. For further details, specifically about tolerance analysis and the mathematics discussed in this section, please refer to [24; 25$]$. 
The worst case implies that if all the parts are within their given CW range, then all the assemblies comprising of these parts will fall in the computed worst case $\mathrm{CW}$ range. Statistical case $\mathrm{CW}$ analysis can take advantage of statistical averaging over assemblies of parts, allowing the allocation of larger range for $\mathrm{CW}$ (compare $\Delta \mathrm{CW}$ from equation (A-7) and (A-8)).

The nominal value for the assembly level $\mathrm{CW}$ can be computed by adding the nominal values of $\mathrm{CW}$ of individual parts, as shown in equation (A-1).

$$
C W_{a}=C W_{1}+C W_{2} \ldots . .+C W_{N}
$$

where $C W_{a}$ represents the nominal value of assembly level $\mathrm{CW}$ and $C W_{i}$ for $i=1 \ldots N$ represents $\mathrm{CW}$ for part 1 to $\mathrm{N}$. The maximum and minimum value (i.e. range) of the assembly level CW for the worst case can be obtained as shown in equations (A-2) and (A-3).

$$
\begin{aligned}
& C W_{a \text { max }}=C W_{1 \text { max }}+C W_{2 \max } \ldots . .+C W_{N \text { max }} \\
& C W_{a \text { min }}=C W_{1 \text { min }}+C W_{2 \min } \ldots . .+C W_{N \text { min }}
\end{aligned}
$$

where $C W_{\text {amax }}$ and $C W_{\text {amin }}$ are the maximum and minimum $\mathrm{CW}$ for the assembly, respectively. Similarly $C W_{\text {imax }}$ and $C W_{\text {imin }}$ for $i=1 \ldots N$ represents the maximum and minimum values of $\mathrm{CW}$ for part 1 to $N$. By subtracting equation (A-3) from equation (A2 ), the worst case variation in the assembly level $\mathrm{CW}$ can be obtained as shown in equation (A-4).

$$
\Delta C W_{a}=\Delta C W_{1}+\Delta C W_{2} \ldots . .+\Delta C W_{N}
$$

where $\Delta C W_{a}$ represents the amount of variation in the $\mathrm{CW}$ value of the assembly from its nominal value. Similarly $\Delta C W_{\text {imax }}$ and $\Delta C W_{\text {imin }}$ for $i=1 \ldots N$ represents the amount of variation of $\mathrm{CW}$ for part 1 to $N$. 
Statistical case $\mathrm{CW}$ analysis can be computed by assuming normal distributions to the range of $\mathrm{CW}$ for individual parts, with the mean being the nominal value and $x$ standard deviations spanning the range of $\mathrm{CW}$. Such an assumption of normal distribution in manufacturing environment is justified because of the central limit theorem. For further details please refer to [26]. The mean and the standard deviation of the assembly level $\mathrm{CW}$ can be obtained as shown in equation (A-1) and (A-5), respectively.

$$
\sigma_{a}^{2}=\sigma_{1}^{2}+\sigma_{2}^{2}+\ldots+\sigma_{N}^{2}
$$

Equation (A-5) represents the standard deviations of the $\mathrm{CW}$ distribution for the assembly if the individual $\mathrm{CW}$ of the parts are independent of each other. In case they are not independent, a correlation ( $\rho_{12}, \rho_{23}$, etc.) between each of them would need to be computed. The standard deviation of the assembly $\mathrm{CW}$ would then be computed from equation (A-6).

$$
\sigma_{a}^{2}=\sigma_{1}^{2}+\sigma_{2}^{2}+\ldots+\sigma_{N}^{2}+\sum_{\substack{i=1 . . . \\ j=1 . . N \\ i \neq j}} \rho_{i j} \sigma_{i} \sigma_{j}
$$

When allocating $\mathrm{CW}$, for the worst-case allocation, consider equation (A-4). If all the $\Delta \mathrm{CW}_{i}$ 's are assumed to be equal but unknown values, then each $\Delta \mathrm{CW}$ can be found from a given assembly $\Delta \mathrm{CW}_{\mathrm{a}}$ as

$$
\Delta \mathrm{CW}=\Delta \mathrm{CWa} / \mathrm{N}
$$

For statistical-case allocation, consider equation (A-5). As an example, assume that all the $\Delta \mathrm{CW}_{i}$ 's are equal and unknown. Since the $\Delta \mathrm{CW}_{i}$ 's are equal, their standard deviations are also equal, let's say $\Delta \mathrm{CW}_{i}=6 \sigma$. Then, the value of $\Delta \mathrm{CW}$ can be obtained from a given assembly $\Delta \mathrm{CW}_{\mathrm{a}}$ by substituting $\sigma_{i}\left(=\Delta \mathrm{CW}_{i} / 6\right)$ and $\sigma_{a}\left(=\Delta \mathrm{CW}_{\mathrm{a}} / 6\right)$ values in equation (A-5) as shown in equation (A-8). 


$$
\begin{gathered}
\Delta C W_{a}^{2}=N^{2} \Delta C W^{2} \\
\Delta C W=\frac{\Delta C W_{a}}{\sqrt{N}}
\end{gathered}
$$

